\title{
PRELIMINARY ASSESSMENT OF THE EFFECT OF NOISE ON VELOCITY UNCERTAINTY ON THE NIGERIAN PERMANENT GNSS NETWORK
}

\author{
Swafiyudeen BAWA ${ }^{1) *}$, Lazarus Mustapha OJIGI ${ }^{1)}$, \\ Joseph Danasabe DODO ${ }^{2)}$ and Kola Muideen LAWAL ${ }^{3)}$ \\ ${ }^{1)}$ Department of Geomatics, Ahmadu Bello University, Zaria, Kaduna, Nigeria \\ 2) Centre for Geodesy and Geodynamics, NASRDA, Toro, Bauchi State, Nigeria \\ 3) Department of Physics, Ahmadu Bello University, Zaria, Kaduna, Nigeria \\ *Corresponding author's e-mail: bswafiyudeen@gmail.com
}

\begin{tabular}{|c|c|}
\hline ARTICLE INFO & ABSTRACT \\
\hline Article history: & With the evolution of GNSS technology, geodynamic activities can appropriately be \\
\hline $\begin{array}{l}\text { Received } 12 \text { March } 2019 \\
\text { Accepted } 15 \text { May } 2019 \\
\text { Available online } 29 \text { May } 2019\end{array}$ & $\begin{array}{l}\text { modelled nowadays. GNSS derived time series from which velocities and their } \\
\text { uncertainties are derived, are vital derivatives in geodynamic modelling processes. } \\
\text { Therefore, understanding all the stochastic properties is crucial. Assuming that GNSS }\end{array}$ \\
\hline Keywords: & underestimation of velocity uncertainties. In this contribution, noise behaviour of \\
\hline $\begin{array}{l}\text { NigNET } \\
\text { Time Series } \\
\text { Noise } \\
\text { Velocity } \\
\text { Nigeria }\end{array}$ & $\begin{array}{l}\text { NigNET tracking stations position time series was examined by adopting WN, } \\
\text { FL+WN, WN+RW, WN+PL. Using the maximum likelihood estimate (MLE), Akaike } \\
\text { Information Criteria (AIC) and Bayesian Information Criteria (BIC) the quality of } \\
\text { stochastic model or the goodness of fit of a stochastic model is determined. The } \\
\text { results of this study show that the combination of white plus flicker noise is the best } \\
\text { model for describing the stochastic part of NigNET tracking stations position time } \\
\text { series. }\end{array}$ \\
\hline
\end{tabular}

\section{INTRODUCTION}

Generally, geodetic techniques that are satellitebased are useful tools for glacial isostatic adjustment (Lidberg et al., 2007), tropospheric modelling for numerical weather assimilation (Isioye et al., 2016), crustal motion as a result of earthquakes and tectonic strain rate (Hackl et al., 2011). For modelling crustal motion and strain rate localization, velocities and uncertainties of permanent geodetic monuments derived from Global Navigation Satellite System (GNSS) time series are often utilized (Nikolaidis, 2002; Hackl et al., 2009). Therefore, since velocities are derivatives of repeated GNSS measurement, unbiased velocities and their uncertainties are essential such that proper analysis of position time series can be attained and large variety of errors are reduced (Amiri-Simkooei et al., 2007; Hackl et al., 2011; Nistor and Buda, 2016).

Over the years, permanent GNSS stations (often referred to as Continuously Operating Reference Stations (CORS)) providing spatial and temporal information, have been set up around the world for reference frame realization and model earth geodynamics. However, these dynamics can only be modelled to some reasonable degree and possibly mitigate some errors with correct stochastic and functional models (He et al., 2017). The stochastic part mostly considered as observational noise can be described by noise models (Goudarzi et al., 2015). Most of the stochastic parts of GNSS time series are time correlated. Mis-modelled satellite orbits, mismodelled atmospheric effects, mis-modelled antenna phase centre effect among others are time correlated (Klos et al., 2014; Langbein and Svarc, 2019; Mao et al., 1999).

In Nigeria, an activity to set up a CORS called NIGerian Reference GNSS NETwork (NigNET) which is a system of Continuous GNSS stations (see Fig. 1) commenced in 2008 by Nigeria Office of the Surveyor General of the Federation (OSGoF). The activity was gone for adding to the African Reference Frame (AFREF) and fill in as an essential fiducial system that will characterize and appear another reference outline dependent on space geodetic strategy (Jatau et al., 2010; Bawa et al., 2019).

Often, what is actually measured in a large crustal entity is the motion of geodetic monuments, from which inferential velocity and strain rate localization are done (Mao et al., 1999). With the recent reports of earth tremors (Vanguard News, 2018) and numerous proposal for a new reference frame base on space geodetic technique (Dodo et al., 2011), spatial and temporal analysis of noise on the Nigeria Permanent GNSS stations is yet to be visited 


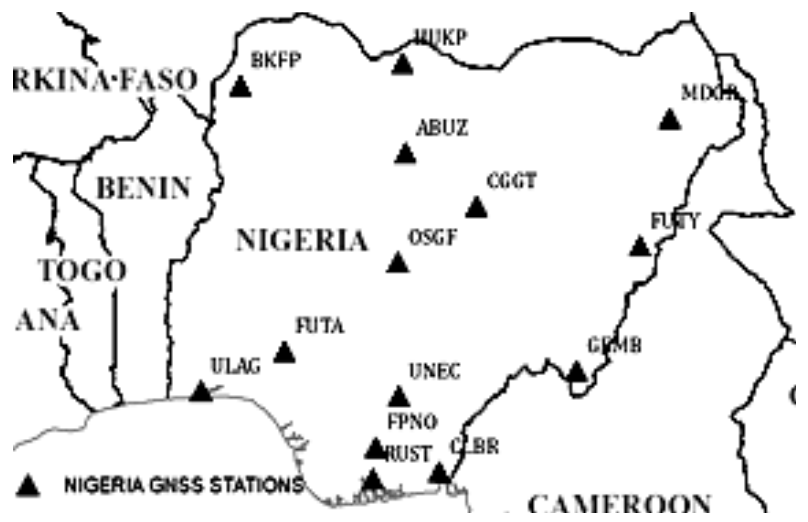

Fig. 1 Spatial distribution of NigNET tracking stations.

as done by (Klos et al., 2014; He et al., 2016; Xu and Yue, 2017)

Klos et al. (2014) who analysed more than 40 stations belonging to the ASG-EUPOS and EPN networks with 5 years of observations from the area of Sudeten, concluded that the $\mathrm{WN}+\mathrm{PL}$ noise best describes the error sources for most of the analysed stations. Elsewhere, Goudarzi et al. (2015) analysed the behaviour of noise in 112 continuously operating GPS (CGPS) position time series in the eastern part of North America and found out that $\mathrm{WN}+\mathrm{FN}$ is the best model that describes the stochastic part of the position time series. $\mathrm{Xu}$ and Yue (2017) in their assessment of the noise characteristics of daily position time series from 12 International GNSS Service sites located in China concluded that the noise model of most sites can be characterized by a combination of $\mathrm{WN}+\mathrm{FN}$.

Therefore, for geophysical studies, it is likely that a variety of time-correlated processes might dominate the error budget. More so, GNSS velocity uncertainties are usually underestimated by factors from 5 to 11 if natural only white noise that is not time correlated is considered as the dominant error source in GNSS (Hackl et al., 2011; Mao et al., 1999; Williams, 2003; Zhang et al., 1997).

To objectively select the best noise model, He et al. (2019) have investigated various criteria such as the log-likelihood value, the Akaike information criterion (AIC) and the Bayesian information criterion (BIC).

The sole aim of this paper is to identify the optimal noise model in the stochastic domain that best describes the NigNET tracking stations. Since more than half of the analyzed time series are less than 5 years (large data gap) on the average and less than $10 y r s$ of data (short data span) (Langbein and Svarc, 2019) the study is considered preliminary.

\section{FUNCTIONAL AND STOCHASTIC MODELS OF NIGNET TIME SERIES \\ FUNCTIONAL MODEL OF TIME SERIES}

The functional model is a constituent of geophysical phenomena present in every GNSS time series (He et al., 2017). Therefore, the daily position of each NigNET station used for this study are combined to form time series of geodetic position using Equation (1) (Goudarzi et al., 2015; Nikolaidis, 2002; Wang, 2015). The XYZ Cartesian coordinate (earth-centered earth-fixed coordinate system) time series are converted to a topocentric coordinate which are cleaned and modelled in all three components $(\mathrm{N}$, E, U) independently using Equation (1).

From the transformed daily coordinate, in Equation (1), velocity and position time series of each GNSS component (North, East and Up) accounting for first order parameters is given by (Goudarzi et al., 2015; Li et al., 2015; Nikolaidis, 2002).

$$
\left[\begin{array}{l}
N \\
E \\
U
\end{array}\right]=\left[\begin{array}{ccc}
-\sin (\lambda) \cos (\phi) & -\sin (\lambda) \sin (\phi) & \cos (\lambda) \\
-\sin (\phi) & \cos (\phi) & 0 \\
\cos (\phi) \cos (\phi) & \cos (\lambda) \cos (\phi) & \sin (\lambda)
\end{array}\right]\left[\begin{array}{l}
X \\
Y \\
Z
\end{array}\right]
$$

$$
\begin{aligned}
y\left(t_{i}\right) & =a+b t_{i}+\sin (2 \pi t)+d \cos \left(2 \pi t_{i}\right)+e \sin \left(4 \pi t_{i}\right)+ \\
& +f \cos \left(4 \pi t_{i}\right)+\sum_{k=1}^{n} j_{k} H\left(t_{i}-t_{j_{k}}\right)+v_{i}
\end{aligned}
$$

Where, $y\left(t_{i}\right)(i=1,2,3, \ldots, N)$ is the position at epoch $\mathrm{t}_{\mathrm{i}}$ in years, $a$ is the station position, $b$ is the linear velocity, $c$ and $d$ are the annual and $e$ and $f$ are the semi-annual amplitudes of sine and cosine functions respectively. $\sum_{k=1}^{N} j_{k} H\left(t_{i}-t_{j_{k}}\right)$ are offsets caused by earthquakes, environmental, equipment malfunction or change, or human intervention (Li et al., 2015), $n$ is the number of offset, $j_{\mathrm{k}}$ is the magnitude change in the position time series at epoch $\mathbf{t}_{\mathbf{j}_{\mathrm{k}}}, \mathrm{H}$ is the Heaviside step function. $\mathbf{v}_{\mathbf{i}}$ signifies measurement error.

$\mathbf{y}=\mathbf{A} \mathbf{x}+\mathbf{v}$

In Equation (3), $\mathbf{x}=\left[\begin{array}{lllllll}\mathbf{a} & \mathbf{b} & \mathbf{c} & \mathbf{d} & \mathbf{e} & \mathbf{f} & \mathbf{j}\end{array}\right]^{\mathbf{T}}, \mathbf{y}$ is the observation matrix and $\mathrm{A}$ is the design matrix, Thus, A can be formulated as given in Equation (4).

Equation (3) is solved using the principle of least squares to estimate the vector of estimated parameters, covariance matrix of the observations, covariance and cofactor matrices of estimated parameters and vector of post-fit residuals.

$A=\left[\begin{array}{ccccccccc}1 & t_{1} & \sin \left(2 \pi t_{1}\right) & \cos \left(2 \pi t_{1}\right) & \sin \left(4 \pi t_{1}\right) & \cos \left(4 \pi t_{1}\right) & H\left(t_{1}-t_{j i}\right) & \ldots & H\left(t_{1}-t_{j} n_{j}\right) \\ \vdots & \vdots & \vdots & \vdots & \vdots & \vdots & \vdots & \ddots & \vdots \\ 1 & t_{N} & \sin \left(2 \pi t_{N}\right) & \cos \left(2 \pi t_{N}\right) & \sin \left(4 \pi t_{N}\right) & \cos \left(4 \pi t_{N}\right) & H\left(t_{N}-t_{j i}\right) & \ldots & H\left(t_{N}-t_{j} n_{j}\right)\end{array}\right]_{N\left(6+n_{j}\right)}$ 


\section{STOCHASTIC MODEL OF TIME SERIES}

GNSS time series are perturbed by random and time correlated noise, this in-turn, results in inaccurate velocity and uncertainty estimate of GNSS observables (Goudarzi et al., 2015). However, removing outliers using designated threshold or criterion can't detect or remove some outliers (He et al., 2017). Therefore, so that realistic uncertainty can be assigned, maximum Likelihood estimation (Bos et al., 2008, 2013), overlapping Hadamard variance (OHVAR) (Xu and Yue, 2017), Least squares variance component estimation (LS-VCE) (AmiriSimkooei et al., 2007) and Alan Variance (Niu et al., 2014) are often used to estimate the optimal noise characteristics in GNSS time series.

Noise analysis in GNSS time series does not reduce the noise but classifying the noise can identify the source of the noise and characterize them, hence, help increase accuracy and precision. Monument instability for example is known to follow the random-walk noise process. So to counter such effect, deep drill braced monuments are recommended for GNSS monuments (Langbein, 2008; Langbein et al., 1995; Williams, 2003; Zhang et al., 1997), this is because deep drill braced geodetic monuments exhibit less temporally correlated noise than any other monument type. The NigNET tracking stations are mostly on roof tops with the exception of station CGGT established on exposed bedrock.

Noise in GNSS position time series can be described as a power-law process (Williams et al., 2004) of the form,

$$
P(f)=P_{o}\left(\frac{f}{f_{o}}\right)^{\kappa}
$$

Where $f_{o}$ and $P_{o}$ are normalized constant, $f$ is the spatial frequency and $\kappa$ is the spectral index. Since GNSS position time series contain both white noise and time correlated noise, considering only white noise will lead to the underestimation of site velocity uncertainties by a factor equivalent to or more than 4 units (Yuan et al., 2008). Thus, there is the need for more robust models to model velocity uncertainties in GNSS. In this regard, numerous models have been proposed (Langbein, 2008; Williams et al., 2004; Zhang et al., 1997). Therefore, noise model in GNSS can be $\mathrm{WN}, \mathrm{WN}+\mathrm{RW}, \mathrm{WN}+\mathrm{FN} \quad \mathrm{WN}+\mathrm{PL}$ $\mathrm{WN}+\mathrm{FN}+\mathrm{RW}$, First-Order Gauss-Markov noise + white noise (FOGM+WN) (He et al., 2017; Williams et al., 2004).

In geophysical phenomena, spectral index range from -3 to +1 . This can further be segregated into fractional Gaussian motion with spectral index of $-1<\kappa<+1$ and fractional Brownian motion with spectral index of $-3<\kappa<-1$ (Goudarzi et al., 2015; Wang, 2015). When $\kappa=0$, the equivalent is termed white noise, when $\kappa=-1$ the equivalent is termed flicker noise, while $\kappa=-2$ is termed random-walk noise or Brownian motion (Mao et al., 1999).
White noise which is not time correlated can be reduced through repeated observations and averaging, is mostly caused by GNSS measurement error and hardware noise (Goudarzi et al., 2015; Mao et al., 1999). Flicker noise is regionally uniform and most common in dynamic process e.g. wobble motion of the earth, sunspot variability, uncertainties in time measure by atomic clock and undersea currents (Nikolaidis, 2002), mis-modelled of satellite antenna phase center, satellite vehicle orbits, Large scale atmospheric effect (Klos et al., 2015).

In this study, HECTOR software (Bos et al., 2013) was used for characterizing GNSS noise model using Maximum Likelihood Estimation given in Equation (6).

$$
\operatorname{lik}(\hat{v}, C)=\frac{1}{(2 \pi) \frac{N}{2}(\operatorname{det} C) \frac{1}{2}} \cdot \exp \left(-0.5 \hat{v}^{T} C^{-1} \hat{v}\right)
$$

Where det is the determinant of a matrix, $\mathrm{C}$ is the covariance matrix of assume noise in data, $\mathrm{N}$ is the number of epochs, $\hat{\mathrm{V}}$ is the time series residuals vector between the data and the functional model. Equation (6) can be rewritten as Equation (7)

$$
\ln [\operatorname{lik}(\hat{v}, C)]=-0.5\left[\ln (\operatorname{det} C)+\hat{v} C^{-1} \hat{v}+N \ln (2 \pi)\right]
$$

Adopting the methods of (Goudarzi et al., 2015; He et al., 2017; Jiang et al., 2014; Klos et al., 2015; Mao et al., 1999; Yuan et al., 2008) four classes of noise models adopted in GNSS applications, namely; $\mathrm{WN}, \mathrm{WN}+\mathrm{PL}, \mathrm{WN}+\mathrm{RW}$ and $\mathrm{WN}+\mathrm{FN}$ are investigated. The choice of these models is based on the notion that they are the most common in GNSS error modelling. The different noise models adopted in this study can be written as the covariance matrix $\mathrm{C}$ (Bos et al., 2008; Klos et al., 2014; Goudarzi et al., 2015) as defined in the maximum likelihood.

To evaluate the quality of a chosen noise model or the goodness of fit of a chosen noise model, the Akaike Information Criteria (AIC) and Bayesian Information Criteria (BIC) (Akaike, 1974; Schwarz, 1978) were used (Bos et al., 2013).

\section{EFFECT OF TIME CORRELATED NOISE ON NigNET VELOCITY}

Zhang et al. (1997), Mao et al. (1999), Williams (2003), Bos et al. (2008), Li and Shen (2012) provided rate uncertainties for different noise models. Thus, following and adopting $\mathrm{Li}$ and Shen (2012), velocity uncertainty of white noise and flicker noise model is calculated as given in the Equations (8) and (9) respectively.

$$
\sigma_{w}=\sqrt{\frac{12 \mathrm{~A}_{w}^{2}}{\Delta t^{2} m\left(m^{2}-1\right)}} \cong \frac{2 \mathrm{~A}_{w}}{\mathrm{~T}} \sqrt{\frac{3}{m}}
$$




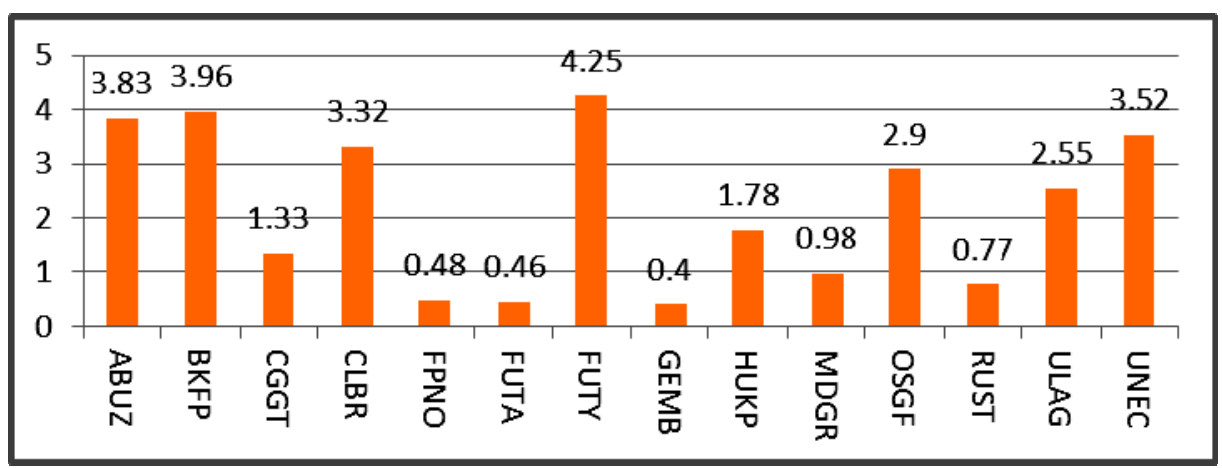

Fig. 2 NigNET data span.

Table 1 Number of Times Each Noise Model. Combination has the Lowest AIC/BIC.

\begin{tabular}{|c|c|c|c|c|c|c|c|c|}
\hline \multirow[t]{2}{*}{ Noise model } & \multicolumn{2}{|c|}{ East(E) } & \multicolumn{2}{|c|}{ North(N) } & \multicolumn{2}{|l|}{$\mathbf{U p}(\mathbf{U})$} & \multicolumn{2}{|c|}{$\%(E, N, U)$} \\
\hline & AIC & BIC & AIC & BIC & AIC & BIC & AIC & BIC \\
\hline WN & 1 & 1 & 2 & 2 & 2 & 3 & $11.5 \%$ & $13.3 \%$ \\
\hline $\mathrm{WN}+\mathrm{PL}$ & 1 & 0 & 1 & 0 & 0 & 0 & $4.5 \%$ & $0 \%$ \\
\hline $\mathrm{WN}+\mathrm{RW}$ & 2 & 3 & 4 & 4 & 5 & 6 & $25 \%$ & $28.9 \%$ \\
\hline $\mathrm{WN}+\mathrm{FL}$ & 11 & 12 & 7 & 8 & 8 & 6 & $59 \%$ & $57.8 \%$ \\
\hline
\end{tabular}

$\sigma_{f}=\sqrt{\frac{1.78 \mathrm{~A}_{f}^{2} \Delta t^{0.22}}{\mathrm{~T}^{2}}} \cong \frac{3 \mathrm{~A}_{f}}{4 \mathrm{~T}}$

For random-walk noise, the uncertainty is given as;

$\sigma_{r w}=\sqrt{\frac{\mathrm{A}_{r w}^{2}}{\Delta t(m-1)}}=\mathrm{A}_{r w} \sqrt{\frac{1}{T}}$

Where $T$ is the total observation span in years, $\Delta t$ is the sampling interval, $m$ is the number of observation $\mathrm{A}_{w}, \mathrm{~A}_{f}$ and $\mathrm{A}_{r w}$ are the amplitudes of white, flicker and random Walk noise respectively.

\section{PRESENTATION OF RESULTS AND DISCUSSIONS TIME SERIES OF NIGNET FROM FUNCTIONAL MODEL}

For time series analysis, NigNET data spanning from $01 / 01 / 2011$ to $12 / 31 / 2015$ were processed using GAMIT/GLOBK. Percentage number of epoch is presented in Figure 2. Co-seismic displacement, power outage, instrument change, direction of motion of station etc., are typical information extractable from GNSS time series.

The time series of all the stations showed no evidence of co-seismic, post-seismic nor inter-seismic displacement in the study periods. Large data gaps in the time series are due to power outage and possibly antenna mal-function and change as was seen in station log file of station CGGN.

\section{ASSESSMENT OF STOCHASTIC MODEL OF NigNET TIME SERIES}

As highlighted earlier, the stochastic models $\mathrm{WN}, \mathrm{WN}+\mathrm{PL}, \mathrm{WN}+\mathrm{RW}$, and $\mathrm{WN}+\mathrm{FL}$ in the form of noise were considered in analysing the geophysical parameters. A threshold of three time inter-quartile range (3IQR) as highlighted earlier is used to remove outliers. Furthermore, the relative goodness of fit of each noise was tested using AIC/BIC. The model with the least $\mathrm{AIC} / \mathrm{BIC}$ is considered the optimal model that describes each time series component.

From Table 1 and Figure 3, it is observed that the optimal noise model that describes the source of noise in estimated geophysical parameter on the NigNET is the WN+FL noise model because the percentage of a number of times $\mathrm{WN}+\mathrm{FL}$ noise model has the lowest $\mathrm{AIC}$ is $59 \%$ and $57.8 \%$ in the $\mathrm{BIC}$ respectively. This is consistent with the studies of $\mathrm{He}$ et al. (2016, 2017), Mao et al. (1999), Wang (2015), Williams et al. (2004) and Zhang et al. (1997).

Questions begin to arise when AIC and BIC are not in agreement as presented in the Table 1 and Figure 3. It is observed that RW+WN (25\%/28.9\%) is the next choice of model followed by white (WN) $(11.5 \% / 13.3 \%)$ AIC/BIC. The results clearly depicts why it is very difficult to consider just one noise model to characterize the error sources in a GNSS station. However, there is a small mean discrepancy between AIC/BIC (1.25 2.85\%) over all stations for the North East and Up components. These values are the reasons why questions arise as to the choice of noise model. An alternate method is the use of visual intuition on the fit of geophysical signal estimate on the observed GNSS time series to make decision (He 


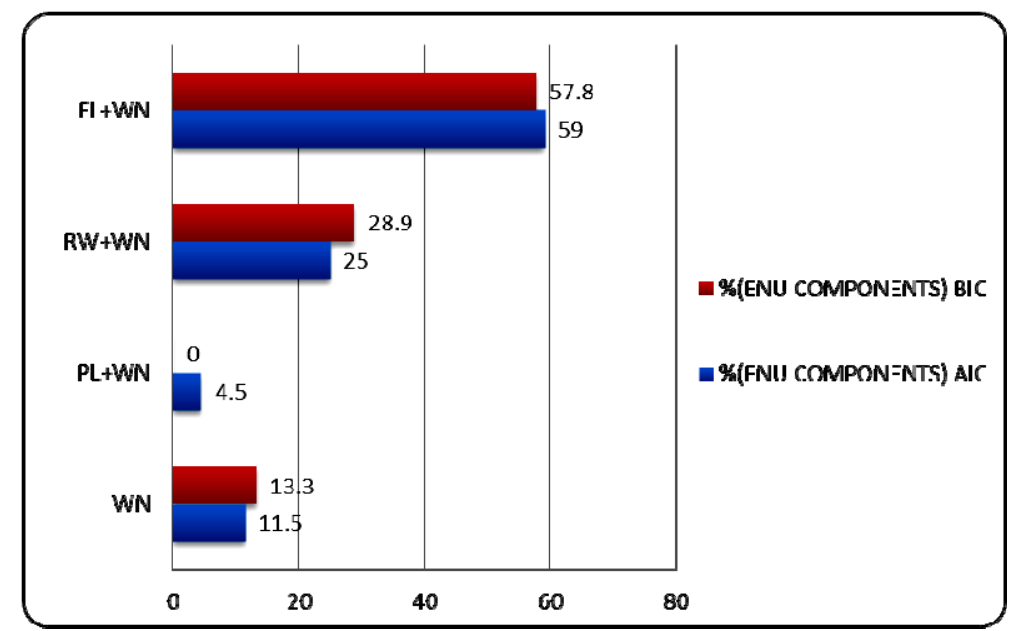

Fig. 3 Bar graph of number of times each noise model combination has the lowest AIC/BIC.

Table 2 Amplitude of white and flicker noise models.

\begin{tabular}{|c|c|c|c|c|c|c|c|c|}
\hline \multirow[t]{2}{*}{ Stations } & \multirow[b]{2}{*}{ Lat } & \multirow[b]{2}{*}{ Long } & \multicolumn{2}{|c|}{ East } & \multicolumn{2}{|c|}{ North } & \multicolumn{2}{|l|}{ Up } \\
\hline & & & White & Flicker & White & Flicker & White & Flicker \\
\hline ABUZ & 11.15174 & 7.64869 & 1.559 & 3.522 & 0.988 & 2.632 & 3.207 & 9.746 \\
\hline BKFP & 12.46858 & 4.22924 & 1.462 & 3.506 & 1.012 & 2.756 & 3.064 & 9.464 \\
\hline CGGT & 10.1231 & 9.11831 & 1.417 & 3.875 & 0.968 & 2.940 & 3.741 & 5.989 \\
\hline CLBR & 4.9503 & 8.35157 & 2.429 & 3.794 & 1.669 & 3.041 & 6.038 & 11.316 \\
\hline FPNO & 5.43457 & 7.03324 & 2.132 & 0 & 1.458 & 3.231 & 6.18 & 0 \\
\hline FUTA & 7.29864 & 5.13644 & 2.748 & 0 & 1.554 & 2.011 & 5.448 & 7.174 \\
\hline FUTY & 9.34974 & 12.49780 & 1.793 & 3.899 & 1.166 & 2.966 & 3.65 & 11.215 \\
\hline GEMB & 6.9172 & 11.18394 & 1.972 & 0 & 1.099 & 0 & 4.203 & 5.44 \\
\hline HUKP & 12.92115 & 7.59091 & 1.975 & 3.236 & 1.208 & 3.098 & 3.616 & 9.484 \\
\hline MDGR & 11.83809 & 13.1310 & 1.499 & 3.176 & 0.965 & 3.358 & 3.266 & 7.739 \\
\hline OSGF & 9.02767 & 7.48634 & 1.849 & 3.361 & 0.836 & 2.285 & 3.976 & 10.336 \\
\hline RUST & 4.80184 & 6.97852 & 1.624 & 4.929 & 1.379 & 3.049 & 6.027 & 0 \\
\hline ULAG & 6.51733 & 3.39762 & 1.937 & 3.037 & 1.218 & 2.762 & 3.994 & 10.985 \\
\hline UNEC & 6.42481 & 7.50499 & 1.848 & 4.299 & 1.257 & 3.293 & 4.436 & 10.344 \\
\hline
\end{tabular}

et al., 2017). Figure 4 is a typical example of spectral plots of stations ABUZ and BKFP of the NigNET tracking stations. The plots show how well each noise model fits into the observed time series. As can be seen in the spectral plot of station ABUZ for example, flicker WN+FN optimally describes it, but WN+RW best describes the noise in the vertical component.

\section{SPATIAL DEPENDENCE OF NigNET NOISE AMPLITUDE}

The question as to whether there is spatial dependence of amplitudes in a global case as pointed out by Mao et al. (1999) and Williams et al. (2004) is applicable to the NigNET case is significant. Interestingly, as presented in Figure 5, there is a significant spatial dependence between the amplitude of white noise in the Up component which corroborates the finding of Mao et al. (1999) and Williams et al. (2004). As for the North and East components, the dependence of amplitude on these components is not obvious. Furthermore, Figure 6 shows that $\mathrm{FN}$ has no convincing significant variation in latitude (see also Table 2), hence corroborates the findings of Williams et al. (2004). Therefore, the finding in the present study is conclusively in conformity with the global generalization of Mao et al. (1999) and Williams et al. (2004). Note that the East, North and Up labels in Figures 5 and 6 are East amplitude, North amplitude and Up amplitude respectively.

\section{EFFECT OF TIME CORRELATED NOISE ON NigNET VELOCITY}

To further investigate the influence of the estimated geophysical parameters, the velocity of individual stations and their uncertainties considering the various noise models adopted in this study were compared. Considering only white noise as the error source in GNSS time series could result to underestimation of velocity errors by a factor of $5-11 \mathrm{~mm} / \mathrm{yr}$ (Mao et al., 1999). This is analogous to Bos et al. (2008), where it was justified that considering only flicker noise could also result to underestimation of velocity uncertainty by factor of 6$13 \mathrm{~mm} / \mathrm{yr}$.

In this study, Equations (8), (9) and (10) are used to compute the velocity uncertainties as presented in Table 3 and subsequently used to plot the velocity vectors as presented in Figures 7, 8 and 9 for $\mathrm{WN}$, $\mathrm{WN}+\mathrm{RW}$, and $\mathrm{WN}+\mathrm{FN}$ model respectively. 


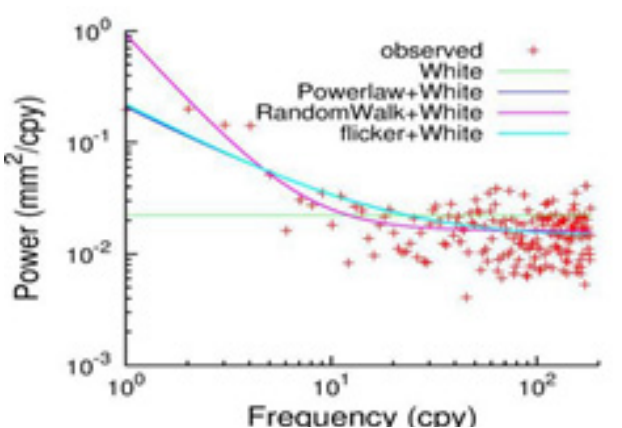

$\left(a_{1}\right)$ Spectral plot for ABUZ East

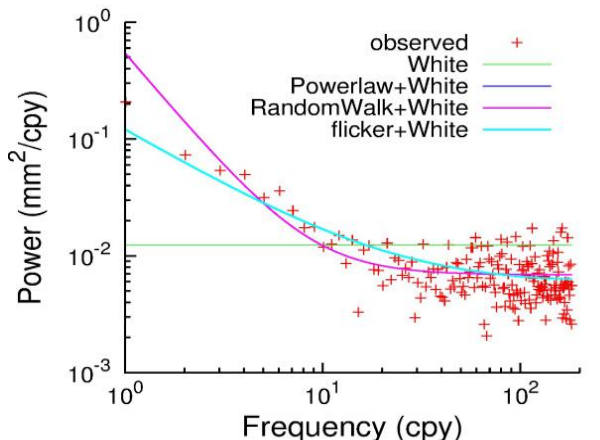

$\left(\mathrm{a}_{2}\right)$ Spectral plot for ABUZ North

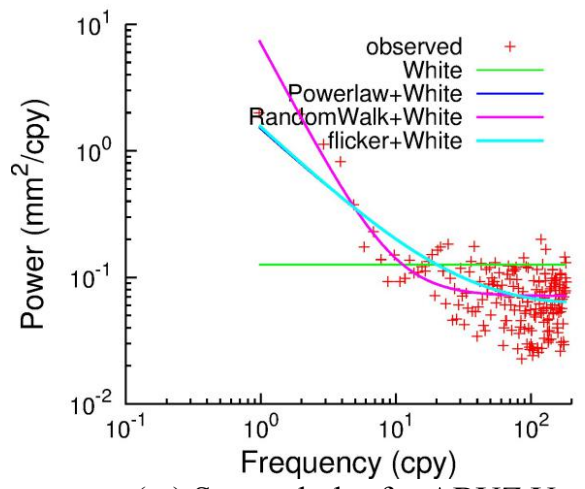

$\left(a_{3}\right)$ Spectral plot for ABUZ Up

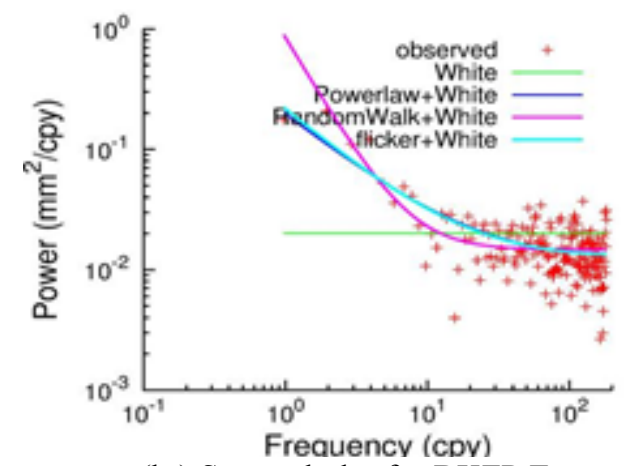

$\left(b_{1}\right)$ Spectral plot for BKFP East

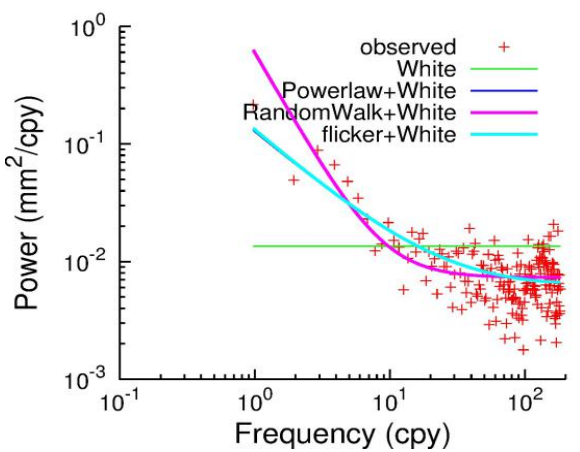

$\left(b_{2}\right)$ Spectral plot for BKFP North

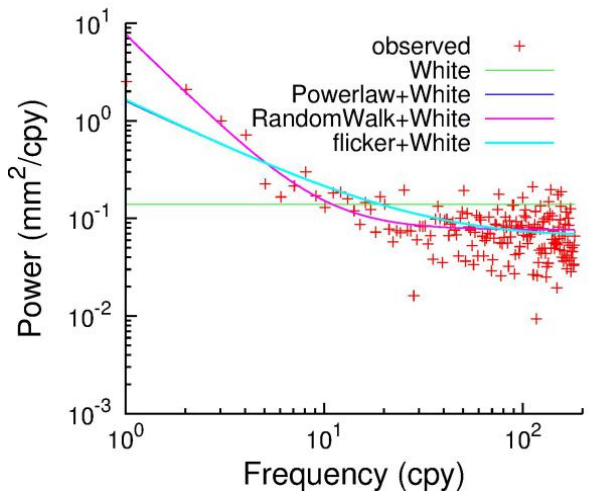

$\left(b_{3}\right)$ Spectral plot for BKFP Up

Fig. 4 Power spectral density (PSD) of residual time-series of stations ABUZ and BKFP in the North, East and Up component, respectively.

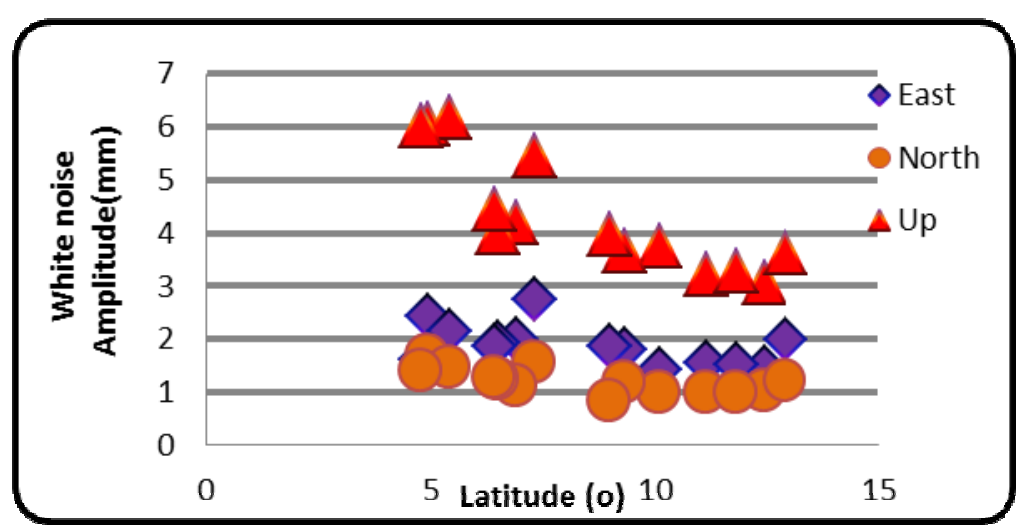

Fig. 5 Latitude dependence of white noise amplitude.

When only white noise is considered, model results to underestimation of velocity uncertainty by a factor of $7 \mathrm{~mm} / \mathrm{yr}, 6 \mathrm{~mm} / \mathrm{yr}$ and $6 \mathrm{~mm} / \mathrm{yr}$ on the average for the East, North and Up components respectively for the case of $\mathrm{WN}+\mathrm{RW}$ noise. More so, assuming only $\mathrm{WN}$ model results to underestimation of velocity uncertainty by a factor $4 \mathrm{~mm} / \mathrm{yr}, 5 \mathrm{~mm} / \mathrm{yr}$ and $4 \mathrm{~mm} / \mathrm{yr}$ on the average for the East, North and Up component respectively for the case of $\mathrm{WN}+\mathrm{FN}$. This corroborates the findings of Mao et al. (1999) and Bos et al. (2008). 


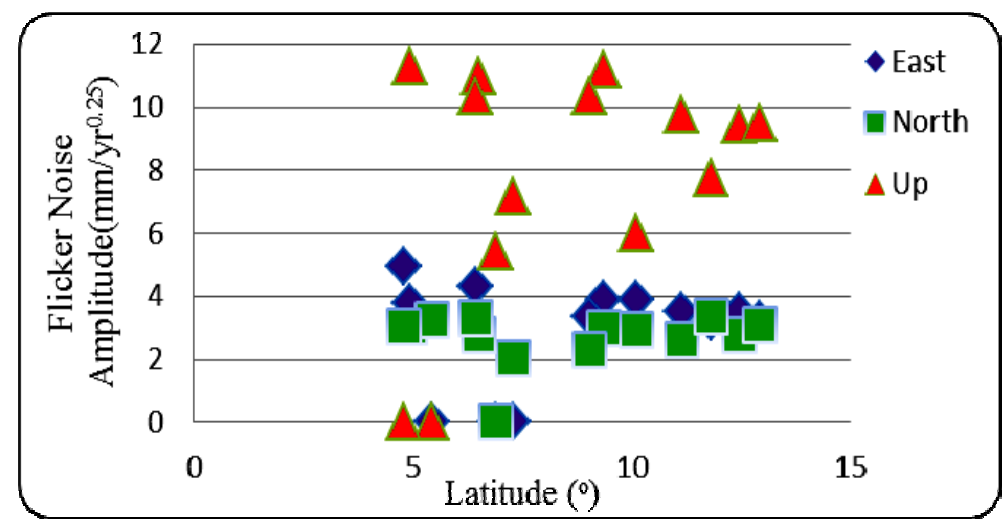

Fig. 6 Latitude dependence of flicker noise amplitude.

Table 3 Velocity uncertainties from different noise model.

\begin{tabular}{|c|c|c|c|c|c|c|c|c|c|c|c|c|}
\hline \multirow{2}{*}{ Station } & \multirow{2}{*}{ Long } & \multirow{2}{*}{ Lat } & \multicolumn{3}{|c|}{ WH } & \multicolumn{3}{|c|}{$\mathrm{WH}+\mathrm{RW}$} & \multicolumn{3}{|c|}{$\mathrm{WH}+\mathrm{FL}$} & \multirow{2}{*}{$\begin{array}{l}\text { Data } \\
\text { Span } \\
\text { (yrs) }\end{array}$} \\
\hline & & & $\mathrm{E}$ & $\mathrm{N}$ & $\mathrm{U}$ & $\mathrm{E}$ & $\mathrm{N}$ & $\mathrm{U}$ & $E$ & $\mathrm{~N}$ & $\mathrm{U}$ & \\
\hline ABUZ & 7.649 & 11.152 & 0.05 & 0.036 & 0.051 & 2.190 & 1.691 & 6.592 & 0.727 & 0.539 & 1.986 & 3.83 \\
\hline BKFP & 4.229 & 12.469 & 0.044 & 0.036 & 0.044 & 2.070 & 1.737 & 5.975 & 0.698 & 0.545 & 1.863 & 3.96 \\
\hline CGGT & 9.118 & 10.123 & 0.257 & 0.203 & 0.257 & 4.185 & 2.338 & 6.174 & 2.353 & 1.772 & 3.819 & 1.33 \\
\hline CLBR & 8.352 & 4.950 & 0.082 & 0.061 & 0.082 & 2.099 & 1.607 & 6.895 & 0.930 & 0.737 & 2.737 & 3.32 \\
\hline FPNO & 7.033 & 5.435 & 1.166 & 0.962 & 1.166 & 1.166 & 3.648 & 3.381 & 1.166 & 5.846 & 3.381 & 0.48 \\
\hline FUTA & 5.136 & 7.299 & 1.606 & 0.979 & 1.606 & 1.606 & 0.979 & 3.442 & 1.606 & 4.187 & 14.881 & 0.46 \\
\hline FUTY & 12.498 & 9.350 & 0.047 & 0.034 & 0.047 & 2.164 & 1.666 & 7.207 & 0.725 & 0.548 & 2.055 & 4.25 \\
\hline GEMB & 11.184 & 6.917 & 0.926 & 0.785 & 0.926 & 1.409 & 0.785 & 3.252 & 1.409 & 0.785 & 13.202 & 0.4 \\
\hline HUKP & 7.591 & 12.921 & 0.274 & 0.200 & 0.274 & 2.884 & 2.597 & 8.927 & 1.607 & 1.454 & 4.442 & 1.78 \\
\hline MDGR & 13.131 & 11.838 & 0.341 & 0.286 & 0.341 & 4.064 & 3.661 & 8.613 & 2.711 & 2.750 & 6.534 & 0.98 \\
\hline OSGF & 7.486 & 9.028 & 0.081 & 0.055 & 0.081 & 1.956 & 1.319 & 6.975 & 0.937 & 0.622 & 2.819 & 2.9 \\
\hline RUST & 6.979 & 4.802 & 0.597 & 0.467 & 0.597 & 6.937 & 2.936 & 1.601 & 5.232 & 3.336 & 1.601 & 0.77 \\
\hline ULAG & 3.398 & 6.517 & 0.097 & 0.071 & 0.097 & 1.931 & 2.247 & 7.676 & 0.979 & 0.867 & 3.409 & 2.55 \\
\hline UNEC & 7.505 & 6.425 & 0.066 & 0.054 & 0.066 & 2.753 & 2.035 & 6.284 & 0.967 & 0.736 & 2.326 & 3.52 \\
\hline
\end{tabular}

Even though $\mathrm{WN}+\mathrm{FN}$ is the optimum noise model to characterize error source in NigNET tracking stations, from Table 3, the largest uncertainties are the most obvious from the combination of $\mathrm{WN}+\mathrm{FN}$. Similarly, Figures 10, 11 and 12 are bar graphs depicting compared uncertainties from the choice of the noise models as computed from Equations (8), (9) and (10). In Figure 11, the velocity uncertainty for stations FPNO and FUTA are the same for the entire models. More so, in Figure 11, the station FUTA shows that the uncertainties for $\mathrm{WN}$ and $\mathrm{WN}+\mathrm{RW}$ are alike. Also, station GEMB has same velocity uncertainty for the noise model. Furthermore, the uncertainties when $\mathrm{WN}+\mathrm{FN}$ and $\mathrm{WN}+\mathrm{RW}$ models are the same for station FPNO.

\section{SUMMARY}

GNSS derived time series from which velocity and their uncertainties are derived an important derivatives in geophysical applications such as crustal motion plate among others. Understanding the stochastic part is essential so that realistic uncertainty can be attained. This paper identifies the optimal stochastic noise model best describes the NigNET tracking stations. The results of this study show that the combination of $\mathrm{W}+\mathrm{FN}$ is the optimal noise model that describes the stochastic part of NigNET tracking stations position time series.

\section{ACKNOWLEDGMENTS}

The authors acknowledge the Office of the Surveyor General of Nigeria for providing the GNSS data used in this research. We would also like to thank IGS for providing necessary geodetic products. The anonymous reviewers who helped in improving the manuscript are also appreciated.

\section{REFERENCES}

Akaike, H.: 1974, A new look at the statistical model identification. IEEE Trans. Autom. Control, 19, 6, 716-723.

DOI: $10.1109 /$ TAC.1974.1100705

Amiri-Simkooei, A.R., Tiberius, C.C.J.M. and Teunissen, P.J.G.: 2007, Assessment of noise in GPS coordinate time series: Methodology and results. J. Geophys. Res. Solid Earth, 112, B7.

DOI: $10.1029 / 2006 J$ B004913

Bawa, S., Ojigi, L.M., Dodo, J.D. and Lawal, K.M.: 2019, Realisation of time-dependent geocentric datum 


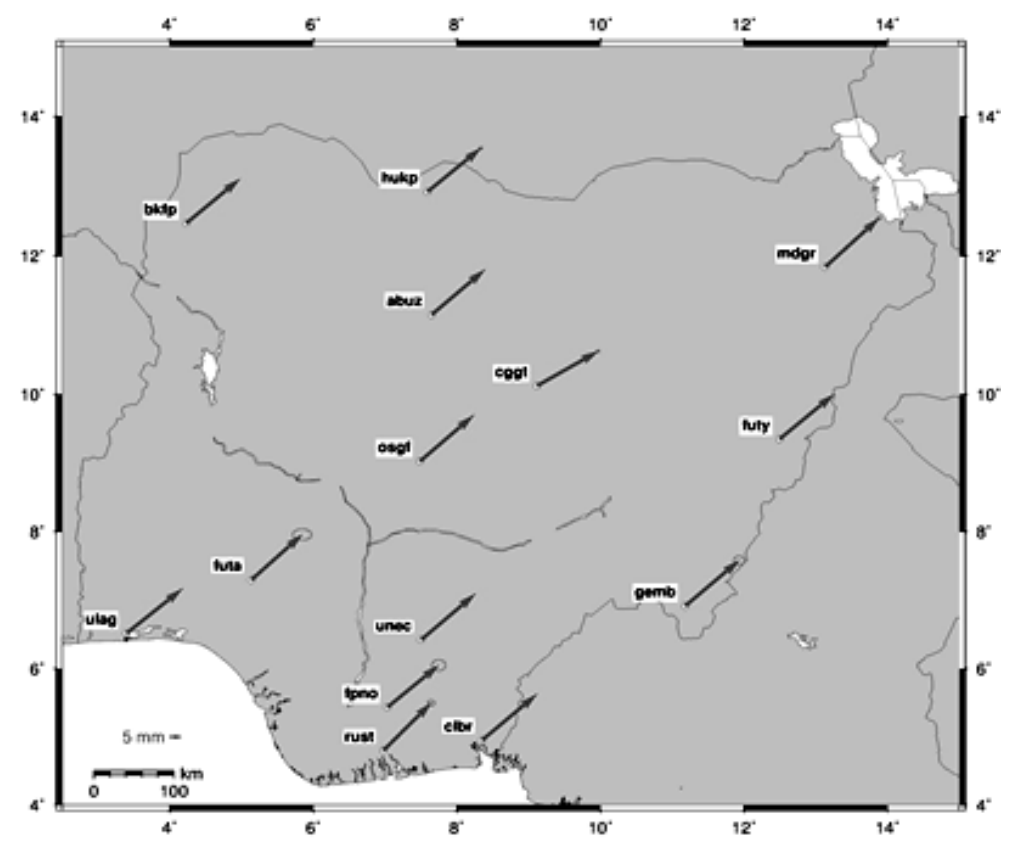

Fig. 7 Velocity field of NigNET stations and their uncertainty for white noise model only at $95 \%$ confidence interval.

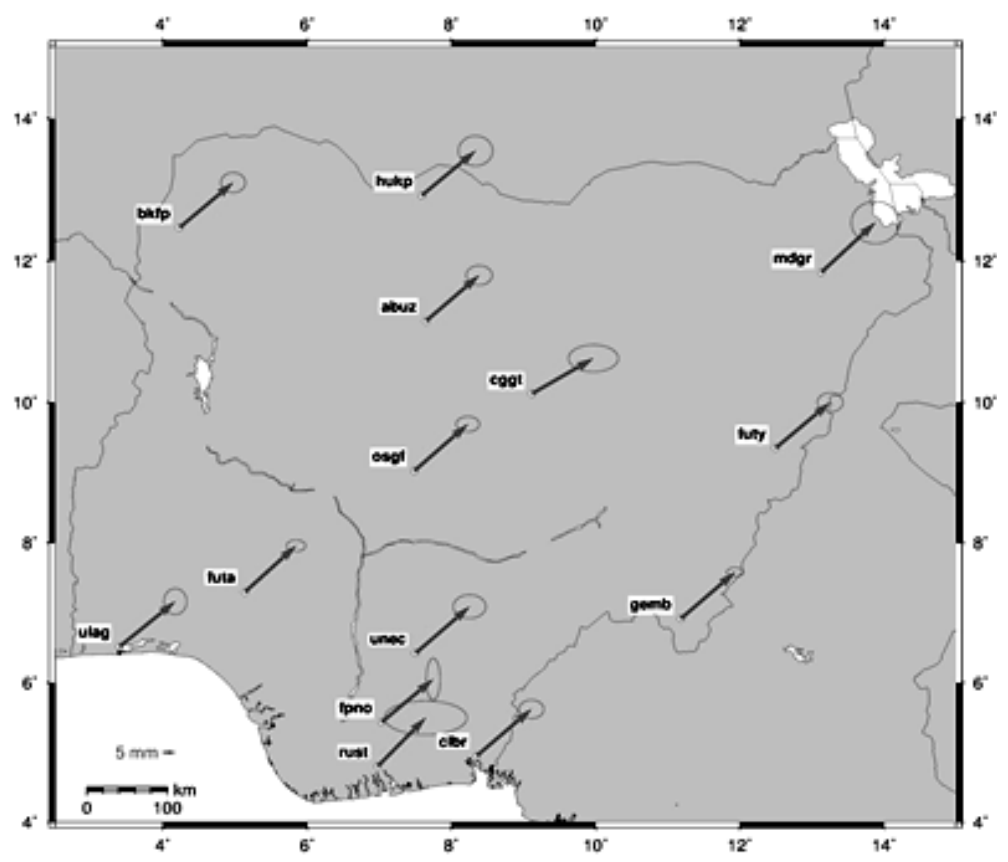

Fig. 8 Velocity field of NigNET stations and their uncertainty for white plus randomwalk noise model only.

transformation parameters for Nigeria. IN: Exploring the Frontiers of Surveying and Geoinformatics for sustainable development, 21, Minna 2019.

Bos, M.S., Fernandes, R.M.S., Williams, S.D.P. and Bastos, L.: 2008, Fast error analysis of continuous GPS observations. J. Geod., 82, 3, 157-166. DOI: $10.1007 / \mathrm{s} 00190-007-0165-\mathrm{x}$

Bos, M.S., Fernandes, R.M.S., Williams, S.D.P. and Bastos, L.: 2013, Fast error analysis of continuous GNSS observations with missing data. J. Geod., 87, 4, 351360. DOI: 10.1007/s00190-012-0605-0

Dodo, J.D., Yakubu, T.A., Usifoh, E.S. and Bojude, A.: 2011, ITRF 2008 realization of the Nigerian Geocentric Datum (GDN2012) : preliminary results. J. Emerg. Trends Eng. Appl. Sci., 2, 6, 978-986.
Goudarzi, M.A., Cocard, M. and Santerre, R.: 2015, Noise behavior in CGPS position time series: the eastern North America case study. J. Geod. Sci., 5, 1, 119147. DOI: $10.1515 /$ jogs-2015-0013

Hackl, M., Malservisi, R. and Wdowinski, S.: 2009, Strain rate patterns from dense GPS networks. Nat. Hazards Earth Syst. Sci., 9, 4, 1177-1187. DOI: 10.5194/nhess-9-1177-2009

Hackl, M., Malservisi, R., Hugentobler, U. and Wonnacott, R.: 2011, Estimation of velocity uncertainties from GPS time series: Examples from the analysis of the South African TrigNet network. J. Geophys. Res. Solid Earth, 116, B11. DOI: $10.1029 / 2010 J B 008142$ 


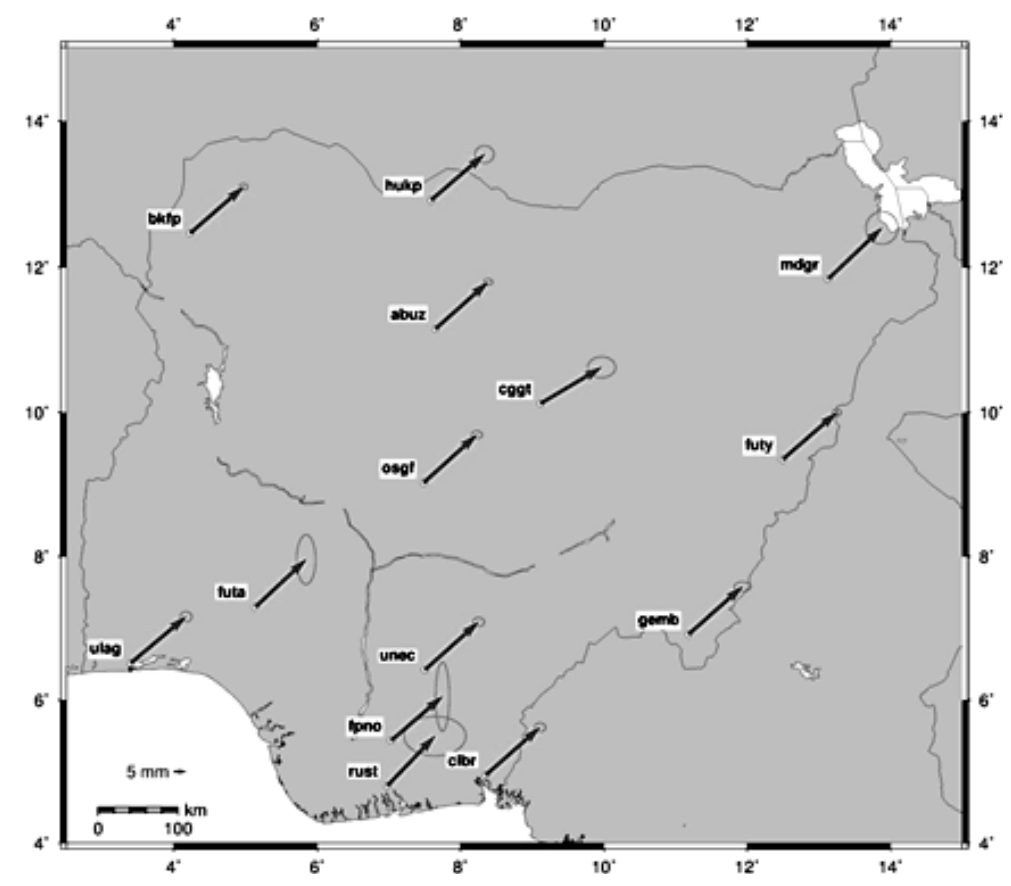

Fig. 9 Velocity field of NigNET stations and their uncertainty for white plus flicker noise model only.

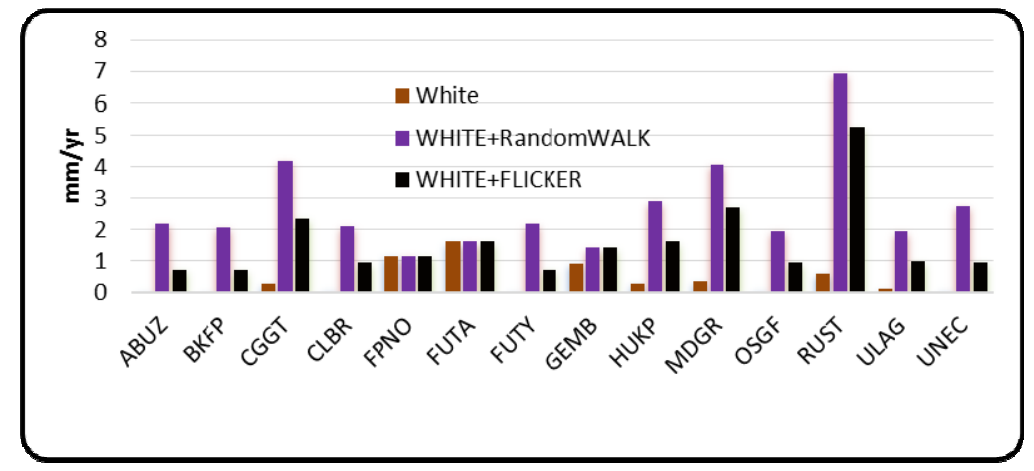

Fig. 10 Comparison of velocity uncertainty in EAST component from the combination of noise models.

He, X., Bos, M.S., Montillet, J.-P. and Fernandes, R.M.S.: 2019, Investigation of the noise properties at low frequencies in long GNSS time series. J. Geodesy. DOI: 10.1007/s00190-019-01244-y

He, X., Montillet, J.-P., Hua, X., Yu, K., Jiang, W. and Zhou, F.: 2016, Noise analysis for environmental loading effect on GPS time series. Acta Geodyn. Geomater., 14, 1, 131-142. DOI: $10.13168 /$ AGG.2016.0034

He, X., Montillet, J.-P., Fernandes, R., Bos, M., Yu, K., Hua, X. and Jiang, W.: 2017, Review of current GPS methodologies for producing accurate time series and their error sources. J. Geodyn., 106, 12-29. DOI: $10.1016 /$ j.jog.2017.01.004

Isioye, O.A., Combrinck, L. and Botai, J.: 2016, Modelling weighted mean temperature in the West African region: implications for GNSS meteorology. Meteorol. Appl., 23, 4, 614-632. DOI: $10.1002 /$ met.1584

Jatau, B., Fernandes, R.M.S., Adebomehin, A. and Goncalves, N.: 2010, NIGNET-The New Permanent GNSS Network of Nigeria. IN: Facing the Challenges Building the Capacity, Sydney, Australia, 11-16 April., 2010.
Jiang, W., Deng, L., Li, Z., Zhou, X. and Liu, H.: 2014, Effects on noise properties of GPS time series caused by higher-order ionospheric corrections. Adv. Space Res., 53, 7, 1035-1046. DOI: $10.1016 / j$.asr.2013.12.037

Klos, A., Bogusz, J., Figurski, M. and Kosek, W.: 2014, Uncertainties of geodetic velocities from permanent GPS observations: The Sudeten case study. Acta Geodyn. Geomater., 11, 3, 201-209.

DOI: 10.13168/AGG.2014.0005

Klos, A., Bogusz, J., Figurski, M., Gruszczynska, M. and Gruszczynski, M.: 2015, Investigation of noises in the EPN weekly time series. Acta Geodyn. Geomater., 12, 2, 117-126. DOI: 10.13168/agg.2015.0010

Langbein, J.: 2008, Noise in GPS displacement measurements from Southern California and Southern Nevada. J. Geophys. Res. Solid Earth, 113, B5. DOI: 10.1029/2007JB005247

Langbein, J. and Svarc, J.L.: 2019, Evaluation of temporally correlated noise in Global Navigation Satellite System time series: Geodetic monument performance. J. Geophys. Res. Solid Earth, 124, 1, 925-942. DOI: 10.1029/2018JB016783 


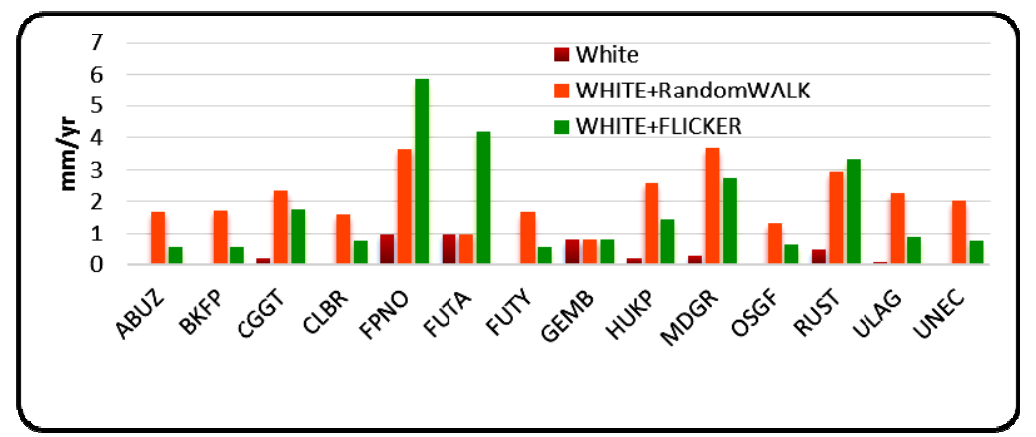

Fig. 11 Comparison of velocity uncertainty in north component from the combination of noise models.

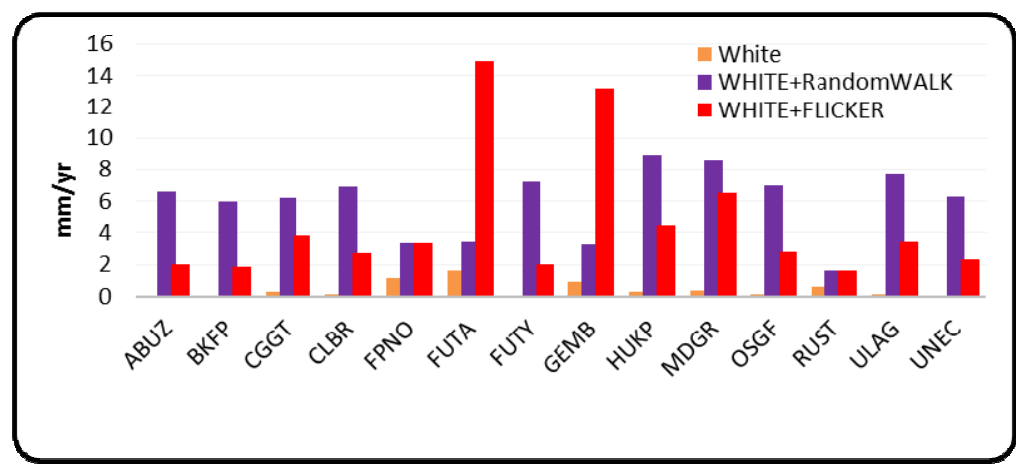

Fig. 12 Comparison of velocity uncertainty in Up component from the combination of noise models.

Langbein, J., Wyatt, F., Johnson, H., Hamann, D. and Zimmer, P.: 1995, Improved stability of a deeply anchored geodetic monument for deformation monitoring. Geophys. Res. Lett., 22, 24, 3533-3536. DOI: 10.1029/95GL03325

Li, W. and Shen, Y.: 2012, The consideration of formal errors in spatiotemporal filtering using principal component analysis for Regional GNSS Position Time Series. Remote Sens., 10, 4, 534. DOI: $10.3390 / \mathrm{rs} 10040534$

Li, W., Shen, Y. and Li, B.: 2015, Weighted spatiotemporal filtering using principal component analysis for analyzing regional GNSS position time series. Acta Geod. Geophys., 50 , 4, 419-436. DOI: $10.1007 / \mathrm{s} 40328-015-0100-1$

Lidberg, M., Johansson, J., Scherneck, H.-G. and Davis, J. L.: 2007, An improved and extended GPS-derived 3D velocity field of the glacial isostatic. J. Geod., 81, 3, 213-230. DOI: 10.1007/s00190-006-0102-4

Mao, A., Harrison, C.G.A. and Dixon, T. H.: 1999, Noise in GPS coordinate time series. J. Geophys. Res. Solid Earth, 104, B2, 2797-2816. DOI: $10.1029 / 1998 J B 900033$

Nikolaidis, R.: 2002, Observation of geodetic and seismic deformation with the Global Positioning System. Ph.D. Thesis, University of California, San Diego.

Nistor, S. and Buda, A.S.: 2016, The influence of different types of noise on the velocity uncertainties in GPS time series analysis. Acta Geodyn. Geomater., 13, 4, 387-394. DOI: 10.13168/AGG.2016.0021

Niu, X., Chen, Q., Zhang, Q., Zhang, H., Niu, J., Chen, K., Shi, C. and Liu, J.: 2014, Using Allan variance to analyze the error characteristics of GNSS positioning. GPS Solut., 18, 2, 231-242.

DOI: $10.1007 / \mathrm{s} 10291-013-0324-\mathrm{x}$
Schwarz, G.: 1978, Estimating the dimension of a model. Ann. Stat., 6, 2, 461-464.

Vanguard News: 2008, Abuja tremor update: Nigeria not earthquake prone - FG. Vanguard News Niger.

Wang, G.: 2015, Noise characterization of GPS time series from the second IGS reprocessing campaign. DOI: $10.18419 /$ opus-3984

Williams, S.D.P.: 2003, The effect of coloured noise on the uncertainties of rates estimated from geodetic time series. J. Geod., 76, 9, 483-494.

DOI: $10.1007 / \mathrm{s} 00190-002-0283-4$

Williams, S.D.P., Bock, Y., Fang, P., Jamason, P., Nikolaidis, R.M., Prawirodirdjo, L., Miller, M. and Johnson, D.J.: 2004, Error analysis of continuous GPS position time series. J. Geophys. Res. Solid Earth, 109, B3. DOI: 10.1029/2003JB002741

$\mathrm{Xu}, \mathrm{C}$. and Yue, D.: 2017, Characterizing noise in daily GPS position time series with overlapping Hadamard variance and maximum likelihood estimation. Surv. Rev., 49, 355, 239-248.

DOI: 10.1080/00396265.2016.1163830

Yuan, L.-G., Ding, X.-L., Chen, W., Kwok, S., Chan, S.-B., Hung, P.-S. and Chau, K.-T.: 2008, Characteristics of daily Position Time Series from the Hong Kong GPS Fiducial Network. Chin. J. Geophys., 51, 5, 976-990. DOI: $10.1002 /$ cjg2.1292

Zhang, J., Bock, Y., Johnson, H., Fang, P., Williams, S., Genrich, J., Wdowinski, S. and Behr, J.: 1997, Southern California permanent GPS geodetic array: Error analysis of daily position estimates and site velocities. J. Geophys. Res. Solid Earth, 102, B8, 18035-18055. DOI: 10.1029/97JB01380 